\title{
EFFICACY OF HANDMADE ANTIBIOTIC PMMA BEADS IN TREATMENT OF CHRONIC OSTEOMYELITIS
}

\author{
Abhilekh Mishra1, Sameer Gupta ${ }^{2}$ \\ ${ }^{1}$ Assistant Professor, Department of Orthopaedics, G. R. Medical College, Gwalior. \\ 2 Professor and HOD, Department of Orthopaedics, G. R. Medical College, Gwalior.
}

\begin{abstract}
BACKGROUND

The term osteomyelitis literally implies inflammation of bone and its bone marrow. The infection involves the marrow space, the Haversian system, and the subperiosteal space. The bone is involved secondarily.(1) Chronic osteomyelitis generally cannot be eradicated without surgery, that is sequestrectomy and resection of scarred and infected bone and soft tissue. The hall mark of osteomyelitis is infected dead bone with in a compromised soft tissue envelope. This avascular envelope of scar tissue leaves systemic antibiotic essentially ineffective. Antibiotic impregnated bone cement beads, specifically designed to combat infection localised to bone and soft tissue, have beads, developed to counter these challenges.
\end{abstract}

\section{MATERIALS AND METHODS}

Study consists of total 40 patients of chronic osteomyelitis treated with PMMA Beads. In our study, all the patients had pus discharge. Mean age for the patients was 30.80 years (10 - 65 years) and male to female ratio was 4.71:1 (Male : 33, female : 7). Most common involved bone was femur (12 patients) followed by tibia (10 patients) and humerus (4 patients). On pus culture, 33 patients had Staphylococcus growth, 4 patients had Streptococci growth while 3 patients' pus culture showed no growth after 48 hours. Radiologically 26 patients had sequestra with cavity, 14 patients had cavity alone while 12 patients had periosteal reaction.

\section{RESULTS}

In our study, 40 patients with haematogenous chronic osteomyelitis of long bone were tested using handmade, vancomycinimpregnated PMMA beads. At 6 months followup, 34 (85\%) patients had good results with clinical and laboratory evidence of healed infection.

\section{CONCLUSION}

Use of antibiotic impregnated PMMA beads offer other advantages that long term parenteral antibiotic therapy is not required, and the patients are not exposed to systemic adverse effects as serum concentration is low and economic savings can be realised as a result of shortened hospital stay, less intensive nursing and reduced use of parenteral antibiotics.

\section{KEYWORDS}

Osteomyelitis, PMMA Beads, Antibiotic Impregnated Cement Bead.

HOW TO CITE THIS ARTICLE: Mishra A, Gupta S. Efficacy of handmade antibiotic PMMA beads in treatment of chronic osteomyelitis. J. Evolution Med. Dent. Sci. 2017;6(54):4082-4085, DOI: 10.14260/Jemds/2017/882

\section{BACKGROUND}

The term osteomyelitis literally implies inflammation of bone and its bone marrow regardless of whether it is due to pyogenic organism, tuberculosis or syphilis, a specific virus or the presence of a foreign body such as Shrapnel; however, universal acceptance of the term is applied only to infection by pyogenic bacteria, less commonly to the granulomatous inflammation of tuberculosis and syphilis. The infection involves the marrow space, the Haversian system, and the subperiosteal space. The bone is involved secondarily.(1) It is destroyed by proteolytic enzymes, necrosed by obliteration of blood supply, decalcified by inactivity and hyperaemia, actively resorbed by osteoclasts and actively reconstructed by osteoblast. It is still a major challenging problem in our country. In majority of cases especially children, it is delay, neglect or inadequate treatment of acute stage and compound fractures that lead to chronicity. When infection

Financial or Other, Competing Interest: None.

Submission 08-05-2017, Peer Review 22-06-2017,

Acceptance 29-06-2017, Published 06-07-2017.

Corresponding Author:

Dr. Abhilekh Mishra,

No. 123, Puruwai Mohalla,

Hazira, Gwalior, Madhya Pradesh.

E-mail: abhilekhorthopaedics@gmail.com

DOI: $10.14260 / \mathrm{jemds} / 2017 / 882$ becomes chronic its eradication becomes a prolonged and tedious affair, causing frustration to the patient as well as to the surgeon. Chronic osteomyelitis generally cannot be eradicated without surgery, that is sequestrectomy and resection of scarred and infected bone and soft tissue. Adequate debridement leaves a large dead space that must be managed to prevent recurrence and significant bone loss that may result in instability.

The hall mark of osteomyelitis is infected dead bone within a compromised soft tissue envelope. This avascular envelope of scar tissue leaves systemic antibiotic essentially ineffective. Antibiotic impregnated bone cement beads, specifically designed to combat infection localised to bone and soft tissue, have beads, developed to counter these challenges. Antibiotic beads are not a substitute for thorough debridement, but they can be very useful in reducing bony ablation, maintaining a germfree wound site, and acting a diaphyseal spacers for later application of bone grafts. Bead chains deliver higher drug concentration to the site of infection, (2-4) yet avoid allergic, ototoxic, and nephrotoxic serum concentrations. In this study, we have tried to evaluate the efficacy of antibiotic impregnated polymethyl methacrylate beads in treatment of chronic osteomyelitis cases and tried to establish the data regarding age, sex, commonly involved bones, duration of disease and tried to 
compare the results of the study with other series in the available literature and with other series using other methods of elimination of dead space in chronic osteomyelitis.

Objective of our study was to evaluate the efficacy of handmade antibiotic impregnated polymethylmethacrylate beads in chronic osteomyelitis and to compare of it with other similar series in the available literature and with other methods of elimination of dead space in chronic osteomyelitis.

\section{MATERIALS AND METHODS}

Study consists of total 40 patients of chronic osteomyelitis treated at Department of Orthopaedics and Traumatology, J. A. group of hospitals, Gwalior from 2014 to 2016. All patients were followed up till 6 months after diagnosis of disease and evaluated throughout the followup period (case series).

\section{Inclusion Criteria}

Haematogenous chronic osteomyelitis involving any long bone in the body, which shows disease activity clinically and a cavity with or without sequestrum radiologically.

\section{Exclusion Criteria}

- Hypersensitivity to components of beads.

- History of toxic reaction to antibiotic.

- Pregnancy or lactation.

- Established hepatic disease.

- Immunosuppressive drugs or medicines.

- Dead space too small to implant beads.

- Acute osteomyelitis.

- Variants of osteomyelitis like Garre's osteomyelitis and Brodie's abscess.

In our study, all the patients had pus discharge. Mean age for the patients was 30.80 years (10 - 65 years) and male to female ratio was $4.71: 1$ (Male: 33 , female: 7). Most common involved bone was femur (12 patients) followed by tibia (10 patients) and humerus (4 patients). On pus culture, 33 patients had Staphylococcus growth, 4 patients had Streptococci growth while 3 patients' pus culture showed no growth after 48 hours. Radiologically 26 patients had sequestra with cavity, 14 patients had cavity alone while 12 patients had periosteal reaction.

In this study, samples of discharge from all sinuses and wounds were taken for culture and antibiotic sensitivity assays and radiographic assessments were made to detect the presence of sequestra.

\section{Surgery was Performed in 2 Stages-}

In first stage, wound was explored, all unhealthy granulation tissue was removed, cavity was decompressed, curetted and thoroughly washed out with copious amount of normal saline.

Roughed and jagged edges of bone was rounded of so as to prevent entanglement of the bead chains. Antibiotic bead chain was then implanted. The number of beads and size of chains were determined depending upon size of cavity. All wounds were closed primarily over suction drain. The limb was immobilised in splint.
In our study, antibiotic impregnated cement beads were handmade. Beads were prepared in operation theatre by mixing Vancomycin $1 \mathrm{~g}$ in amount of $40 \mathrm{~g}$ powder of polymethylmethacrylate. After that activating solution was poured in the mixture. When the mixture became doughy and non-sticky, beads of 5-8 $\mathrm{mm}$ size were hand rolled and threaded on to a knotted steel wire of SWD 24.

Systemic antibiotics to which organisms were sensitive, were given for 7 days. If found to be resistant to all antibiotics, broad spectrum antibiotics were administered. Suction drains were removed after 24-48 hours and beads were removed at least 6 weeks after surgery.

\section{RESULT}

ESR patterns among the patients were as following:

\begin{tabular}{|c|c|c|c|c|}
\hline $\begin{array}{c}\text { Sl. } \\
\text { No. }\end{array}$ & Range & $\begin{array}{c}\text { No. of Patients } \\
\text { at Presentation }\end{array}$ & $\begin{array}{c}\text { No. of Patients } \\
\text { on } 2^{\text {nd }} \text { Week }\end{array}$ & $\begin{array}{c}\text { No. of Patients } \\
\text { on } 6^{\text {th }} \text { Month }\end{array}$ \\
\hline 1 & $<20$ & $00(0 \%)$ & $00(0 \%)$ & $35(87.5 \%)$ \\
\hline 2 & $20-40$ & $16(40 \%)$ & $32(80 \%)$ & $05(12.5 \%)$ \\
\hline 3 & $40-80$ & $21(52.5 \%)$ & $08(20 \%)$ & $00(0 \%)$ \\
\hline 4 & $>80$ & $03(7.5 \%)$ & $00(0 \%)$ & $00(0 \%)$ \\
\hline Mean & \multicolumn{5}{|c|}{ Table 1. ESR Pattern in the Patients at the } \\
\hline \multicolumn{5}{|c|}{ time of Presentation, at 2nd week Followup and $6^{\text {th }}$ week of } \\
Followup
\end{tabular}

CRP patterns among the patients were as following:

\begin{tabular}{|c|c|c|c|c|}
\hline $\begin{array}{l}\text { Sl. } \\
\text { No. }\end{array}$ & CRP Range & $\begin{array}{c}\text { CRP at } \\
\text { presentation }\end{array}$ & $\begin{array}{c}\text { CRP on } \\
2^{\text {nd }} \text { week }\end{array}$ & $\begin{array}{l}\text { CRP on } \\
6^{\text {th }} \text { month }\end{array}$ \\
\hline 1 & $\begin{array}{c}0-1 \\
\text { (Normal) }\end{array}$ & 07 (17.5\%) & $24(60 \%)$ & 35 (87.5\%) \\
\hline 2 & $\begin{array}{c}>1-10 \\
\text { (Moderate) }\end{array}$ & 28 (70\%) & 12 (30\%) & 07 \\
\hline 3 & $\begin{array}{c}>10 \\
\text { (Marked) }\end{array}$ & 05 (12.5\%) & $4(10 \%)$ & $00(0 \%)$ \\
\hline & Mean & 5.4 & 1.82 & 0.6 \\
\hline
\end{tabular}

Condition of sinus among the patients were as following:

\begin{tabular}{|c|c|c|c|}
\hline $\begin{array}{c}\text { Sl. } \\
\text { No. }\end{array}$ & $\begin{array}{c}\text { Clinical condition of } \\
\text { sinus }\end{array}$ & $\begin{array}{c}\text { on } 2^{\text {nd }} \\
\text { week }\end{array}$ & $\begin{array}{c}\text { on 6}^{\text {th }} \\
\text { month }^{\text {mont }}\end{array}$ \\
\hline 1 & Healed & $28(70 \%)$ & $32(80 \%)$ \\
\hline 2 & Persistent & $12(30 \%)$ & $00(0 \%)$ \\
\hline 3 & Recurrent & $00(0 \%)$ & $08(20 \%)$ \\
\hline \multicolumn{3}{|c|}{$\begin{array}{c}\text { Table 3. Condition of Sinus at } 2^{\text {nd }} \text { week } \\
\text { Followup and } 6^{\text {th }} \text { week of Followup }\end{array}$} \\
\hline
\end{tabular}

\begin{tabular}{|c|c|c|c|}
\hline Sl. No. & Result & No. of Patients & Percentage \\
\hline 1 & $\begin{array}{c}\text { Good (healed } \\
\text { sinus, ESR returning } \\
\text { to normal) }\end{array}$ & 34 & $84.62 \%$ \\
\hline 2 & $\begin{array}{c}\text { Fair (recurrence of } \\
\text { sinus \& ESR } \\
\text { returning to normal) }\end{array}$ & 00 & N.A. \\
\hline \multirow{2}{*}{$\begin{array}{c}\text { Poor (persistence of } \\
\text { sinus, ESR persistently } \\
\text { elevated) }\end{array}$} & 06 & $15.38 \%$ \\
\hline \multicolumn{3}{|c|}{$\begin{array}{c}\text { Table 4. Result According to Condition } \\
\text { of Sinus, and ESR Pattern }\end{array}$} \\
\hline
\end{tabular}




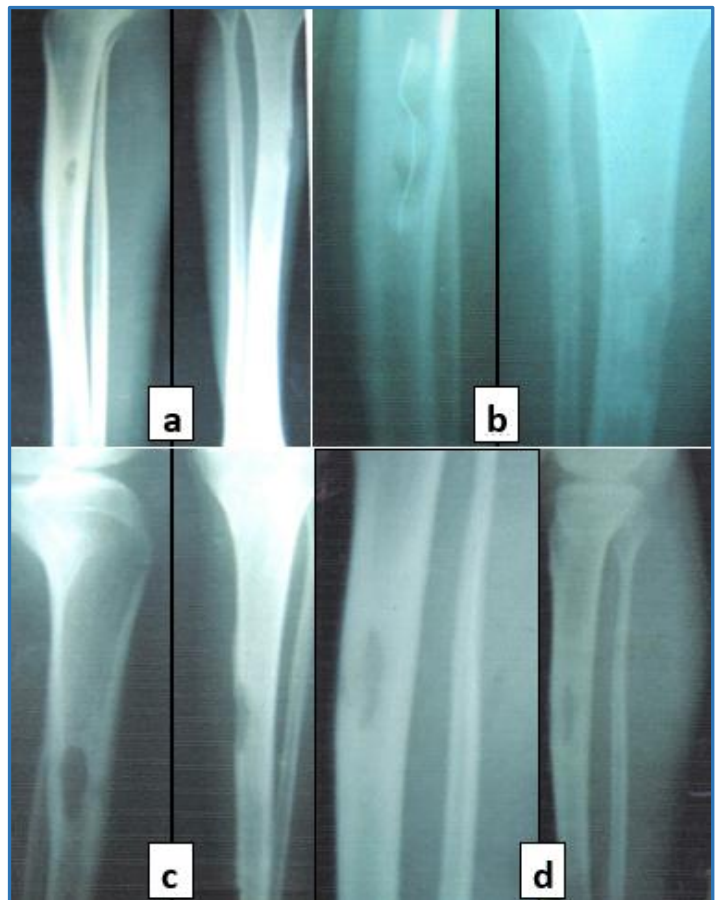

Figure 1. A 43-year-old male with chronic osteomyelitis of shaft tibia was treated with antibiotic impregnated cement beads. (a) Pre-operative $x$-ray, (b) Post-operative $x$-ray, (c) 6 weeks followup after beads removal, (d) $6^{\text {th }}$ month followup $x$-ray.

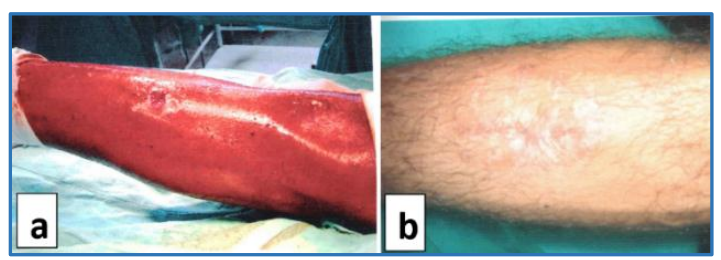

Figure 2. (a) Clinical picture of pus discharging sinus at presentation (b) at $6^{\text {th }}$ week followup healed sinus

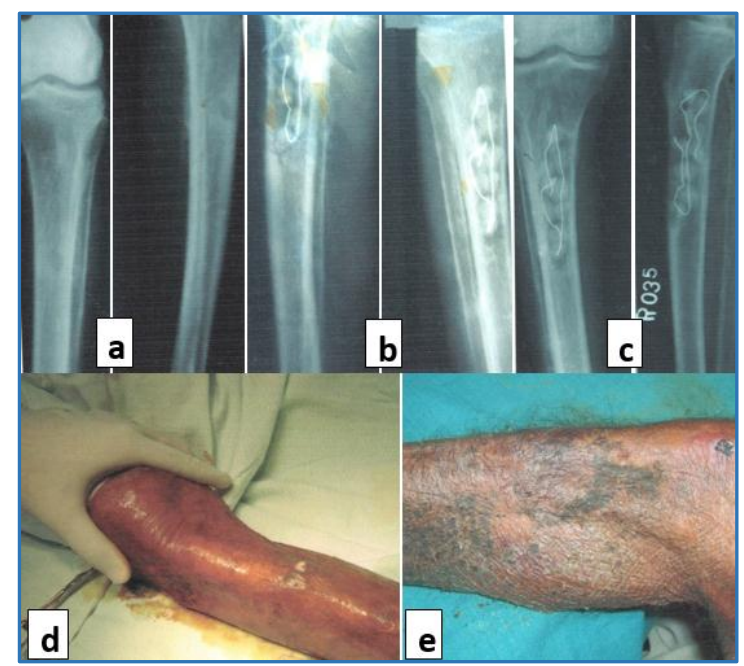

Figure 3. A 34-year-old male with osteomyelitis of tibia was treated with antibiotic impregnated cement beads. (a)

Pre-operative x-ray, (b) Post-operative x-ray, (c) 6 weeks followup $x$-ray, (d) Active pus discharging sinus at presentation, (e) Healed sinus on $6^{\text {th }}$ week.

\section{DISCUSSION}

Chronic osteomyelitis is difficult to treat than other infectious disorder because the systemically administered antibiotics fail to reach the site of infection in adequate concentration owing to relative avascularity. The principle of depot administration of antibiotic is based on a well-accepted fact that drug leaches out locally over a period of time from PMMA beads. The resulting bactericidal tissue concentration is therefore higher than the concentration achieved by systemic antibiotic administration.

Vincent Dacquet et al (1992) studied Plaster of Paris as a vehicle of antibiotic in form of beads for elimination of dead space.

Although a wide assortment of antibiotic leach from a variety of different acrylic bone cement, two aminoglycosides, gentamicin and tobramycin, and one glycopeptide vancomycin have been most widely studied and used.

In our study, 40 patients with haematogenous chronic osteomyelitis of long bone were tested using handmade, vancomycin-impregnated PMMA beads. At 6 months followup, 34 (85\%) patients had good results with clinical and laboratory evidence of healed infection.

David M. Scott et al(5) (1988) studied 3 patients with chronic osteomyelitis using vancomycin and/or tobramycin PMMA bead and at $3^{\text {rd }}$ month all 3 patients had healed infection.

S.P. Mohanty et al(6) (2003) in their study of chronic osteomyelitis in 49 patients treated with implantation of gentamycin-impregnated PMMA beads, reported a success of $87 \%$ with evidence of healed infection. Klemm et al (1979) in his study of 128 cases of chronic osteomyelitis treated with implantation of gentamycin-impregnated PMMA beads, reported a success rate of $91.4 \%$.

Calhaum et al(7) (1993) in their study on 52 patients with osteomyelitis reported that better results (89\% success) obtained in a group of patients treated with gentamycinimpregnated PMMA beads with another group receiving 4-6 weeks of parenteral antibiotics (83\% success rate).

Blaha DJ et al(8) in (1993) studied comparison of clinical efficacy and tolerance of gentamicin-PMMA beads verses combined and systemic therapy for chronic osteomyelitis stated that cost of treatment was considerably less in former group.

Evans et $\mathrm{al}^{9}$ concluded that debridement with the implantation of gentamicin-PMMA beads and debridement followed by systemic antibiotics were significantly more successful forms of treatment for chronic osteomyelitis than debridement alone or debridement with the implantation of PMMA beads not impregnated with antibiotics. Debridement followed by the implantation of PMMA-gentamicin beads and the use of systemic antibiotics produced the greatest success rate. Treatment with a combination of gentamicin-PMMA beads and systemic antibiotics resulted in a $100 \%$ success rate.

However, considerable investigation and development are still required to generate the necessary data to help determine a number of unknown variables associated with the use of local antibiotic delivery vehicles. These unknown variables include the identification of the most ideal biomaterial composites that address the dual goal of unique antibiotic delivery patterns and bone regeneration process. 


\section{CONCLUSION}

In our study, $34(85 \%)$ patients had healed disease at 6 months followup and $6(15 \%)$ patients had persistent discharge from sinus. These 6 patients had pandiaphyseal osteomyelitis. The results of implantation of vancomycinimpregnated PMMA beads are comparable to other methods used for the elimination of dead space following debridement and excision of necrotic tissue. Though the results are comparable, use of antibiotic impregnated PMMA beads offer other advantages that long term parenteral antibiotic therapy is not required, and the patients are not exposed to systemic adverse effects as serum concentration is low and economic savings can be realised as a result of shortened hospital stay, less intensive nursing and reduced use of parenteral antibiotics. However, the term quiescence or remission should be proffered for chronic osteomyelitis rather than cure because osteomyelitis can, and frequently does, recur after a prolonged period with no sign and symptom.

\section{REFERENCES}

[1] Bjorkstén B, Boquist L. Histopathological aspects of chronic recurrent multifocal osteomyelitis. J Bone Joint Surg Br 1980;62(3):376-80.

[2] Kenneth A, Calhoun J, Mader JT. In vitro and in vivo evaluation of antibiotic diffusion from antibioticimpregnated polymethylmethacrylate beads. Clinical Orthopaedics and Related Research 1992.
[3] Baker AS, Greenham LW. Release of gentamicin from acrylic bone cement. Elution and diffusion studies. J Bone Joint Surg Am 1988;70(10):1551-7.

[4] Goodell JA, Flick AB, Hebert JC, et al. Preparation and release characteristics of tobramycin-impregnated polymethylmethacrylate beads. Am J Health Syst Pharm 1986;43(6):1454-61.

[5] Scott DM, Rotschafer JC, Behrens F. Use of vancomycin and tobramycin polymethylmethacrylate impregnated beads in the management of chronic osteomyelitis. Drug Intell Clin Pharm 1988;22(6):480-3.

[6] Mohanty SP, Kumar MN, Murthy NS. Use of antibioticloaded polymethyl methacrylate beads in the management of musculoskeletal sepsis--a retrospective study. J Orthop Surg Hong Kong 2003;11(1):73-9.

[7] Klemm K. The use of antibiotic-containing bead chains in the treatment of chronic bone infections. Clin Microbiol Infect 2001;7(1):28-31.

[8] Blaha JD, Calhoun JH, Nelson CL, et al. Comparison of the clinical efficacy and tolerance of gentamicin-PMMA beads on surgical wire versus combined and systemic therapy for osteomyelitis. Clin Orthop 1993;295:8-12.

[9] Richard EP, Carl NL. Gentamicin-impregnated polymethylmethacrylate beads compared with systemic antibiotic therapy in the treatment of chronic osteomyelitis. Clinical Orthopaedics and Related Research 1993. 